\title{
Correction: A fixed point theorem for cyclic generalized contractions in metric spaces. Fixed Point Theory and Applications 2012, 2012:122
}

Maryam A Alghamdi ${ }^{1}$, Adrian Petruşel ${ }^{2}$ and Naseer Shahzad ${ }^{3 *}$

${ }^{*}$ Correspondence:

nshahzad@kau.edu.sa

${ }^{3}$ Department of Mathematics, King

Abdulaziz University, P.O. Box 80203

Jeddah, 21859, Saudi Arabia

Full list of author information is

available at the end of the article

\section{Abstract}

The purpose of this short note is to present some corrections and clarifications concerning the proof of the main result given in the above mentioned paper.

Concerning the text and the proof of the main result (Theorem 2.2), we would like to do the following corrections and clarifications:

(1) In Theorem 2.2, an additional hypothesis is needed, namely:

3. There exists $y_{1} \in Y$ such that

$$
d\left(y_{1}, f^{n}\left(y_{1}\right)\right)<+\infty \quad \text { for all } n \in \mathbb{N}^{*} .
$$

(2) On page 3, the fact that the sequence $\left(c_{n}\right)_{n \in \mathbb{N}}$ is bounded follows now from the above mentioned hypothesis, using the following remark: by 3 ., for each $x \in Y$, we have that

$$
d\left(x, f^{n}(x)\right)<+\infty \quad \text { for all } n \in \mathbb{N}^{*} .
$$

Indeed, let $n \in \mathbb{N}^{*}$ and suppose that $y_{1} \in A_{1}$. Let $x \in A_{l}$ (where $l \in\{1, \ldots, m\}$ ). Let us choose $u_{2} \in A_{2}, \ldots, u_{l-1} \in A_{l-1}$. Then

$$
\begin{aligned}
d\left(x, f^{n}(x)\right) & \leq d\left(x, y_{1}\right)+d\left(y_{1}, f^{n}\left(y_{1}\right)\right)+d\left(f^{n}\left(y_{1}\right), f^{n}(x)\right) \\
& \leq d\left(x, y_{1}\right)+d\left(y_{1}, f^{n}\left(y_{1}\right)\right)+d\left(f^{n}\left(y_{1}\right), f^{n}\left(u_{2}\right)\right)+\cdots+d\left(f^{n}\left(u_{l-1}\right), f^{n}(x)\right) \leq \cdots \\
& \leq d\left(x, y_{1}\right)+d\left(y_{1}, f^{n}\left(y_{1}\right)\right)+d\left(y_{1}, u_{2}\right)+\cdots+d\left(u_{l-1}, x\right)<+\infty .
\end{aligned}
$$

(3) On page 5, to prove that the Picard iteration converges to $x^{*}$, we have to do as follows.

Let us show now that the Picard iteration converges to $x^{*}$ for any initial point $x_{1}$. We know that $f$ has a unique fixed point (denoted by $x^{*}$ ) and the sequence $\left(x_{n}\right)_{n \in \mathbb{N}}$ converges to a certain $y \in \bigcap_{i=1}^{m} A_{i}$. We will show that $y$ is also a fixed point of $f$. For this purpose, we

\section{Springer}

(c) 2013 Alghamdi et al.; licensee Springer. This is an Open Access article distributed under the terms of the Creative Commons Attribution License (http://creativecommons.org/licenses/by/2.0), which permits unrestricted use, distribution, and reproduction in any medium, provided the original work is properly cited. 
have

$$
d(y, f(y)) \leq d\left(y, x_{n+1}\right)+d\left(f\left(x_{n}\right), f(y)\right) \leq d\left(y, x_{n+1}\right)+d\left(y, x_{n}\right) \rightarrow 0 \quad \text { as } n \rightarrow \infty
$$

This shows that $y$ is a fixed point of $f$ and, thus, $y=x^{*}$.

\section{Competing interests}

The authors declare that they have no competing interests.

\section{Authors' contributions}

All authors contributed equally and significantly in writing this article. All authors read and approved the final manuscript.

\section{Author details}

${ }^{1}$ Department of Mathematics, Sciences Faculty for Girls, King Abdulaziz University, P.O. Box 4087, Jeddah, 21491, Saudi Arabia. ${ }^{2}$ Department of Mathematics, Babeş-Bolyai University, Kogălniceanu Street No. 1, Cluj-Napoca, 400084, Romania.

${ }^{3}$ Department of Mathematics, King Abdulaziz University, P.O. Box 80203, Jeddah, 21859, Saudi Arabia.

Received: 31 January 2013 Accepted: 10 February 2013 Published: 26 February 2013

doi:10.1186/1687-1812-2013-39

Cite this article as: Alghamdi et al.: Correction: A fixed point theorem for cyclic generalized contractions in metric spaces. Fixed Point Theory and Applications 2012, 2012:122. Fixed Point Theory and Applications 2013 2013:39.

\section{Submit your manuscript to a SpringerOpen ${ }^{\circ}$ journal and benefit from:}

- Convenient online submission

- Rigorous peer review

Immediate publication on acceptance

Open access: articles freely available online

- High visibility within the field

- Retaining the copyright to your article 